\title{
Prevalence of Cystic Echinococcosis in Slaughtered Ruminants in Different Abattoirs, Upper Egypt
}

\author{
${ }^{1}$ Mosaab Omar, ${ }^{2}$ Khaled Sultan, ${ }^{3}$ Mohie Haridy and ${ }^{4}$ Alsagher Omran \\ ${ }^{1}$ Department of Parasitology, \\ Faculty of Veterinary Medicine, South Valley University, 83523 Qena, Egypt \\ ${ }^{2}$ Department of Parasitology, \\ Faculty of Veterinary Medicine, Kafrelsheikh University, 33516 Kafr El-Sheikh, Egypt \\ ${ }^{3}$ Department of Pathology, \\ Faculty of Veterinary Medicine, South Valley University, 83523 Qena, Egypt \\ ${ }^{4}$ Department of Animal Medicine, \\ Faculty of Veterinary Medicine, South Valley University, 83523 Qena, Egypt
}

Received 2013-07-21, Revised 2013-07-23; Accepted 2013-07-25

\begin{abstract}
Hydatid disease is a re-emerging disease that infects human and animals world-wide. Cystic Echinococcosis (CE) is the most common form of the disease. In Egypt, CE is an endemic disease and several reports have indicated an increasing prevalence rate of the $\mathrm{CE}$ infection in animals and humans in the last few years. The aim of the current study is to determine the prevalence rate and other epidemiological factors in the infecting of ruminants with CE in different locations in Upper Egypt. The data gathered shows that of 4,498 animals examined, 89 (1.97\%) had the hydatid cyst. Sheep were the most affected animal species (14.1\%), then goats (13\%), camels (5\%) and cattle $(0.068 \%)$, while buffaloes were free from infection. A higher percentage were affected in the liver $(39.3 \%)$ than in the lungs $(32.5 \%)$ and other viscera $(2.2 \%)$, while $25.8 \%$ were affected in both the liver and the lungs The general fertility rate of cysts examined was $27.71 \%$; cysts of camel origin were the most fertile $(66.6 \%)$, followed by those of goats $(29.41 \%)$ and sheep $(15.51 \%)$; that of cattle was $0 \%$. The current study provides current data about the status of CE infection in ruminants in Upper Egypt that will aid further studies and enable more precise planning for effective control strategies.
\end{abstract}

Keywords: Hydatid, Echinococcosis, Cyst, Ruminant, Prevalence

\section{INTRODUCTION}

Hydatid disease is a cosmopolitan zoonoses caused by the larval stage of the Echinococcus tapeworm. The two main types of hydatid disease are caused by $E$. granulosus and E. multilocularis. Cystic Echinococcosis (CE) is the most common form, caused by the larval stage of E. granulosus. It is seen in most regions of the world-particularly the Mediterranean region, Africa and the Middle East-and it is the most frequently encountered form of hydatidosis in humans (FAO, 1982; Thompson, 1995; Torgerson and Budke, 2003; Haridy et al., 2006).
$\mathrm{CE}$ is re-emerging as a major public health issue (Torgerson and Budke, 2003). Despite efforts to control CE, the disease continues to threaten human health in a number of countries, including Egypt. In the last few years, several cases of human CE have been reported (at least 18 in the last 5 years) and treated in the hospitals of Cairo and the Delta regions (Elshazly et al., 2009). In Upper Egypt, a serological survey showed that $5 \%$ of human samples tested positive for E. granulosus (Dyab et al., 2005).

Ruminants are the main intermediate host for $E$. granulosus in Egypt (Rahman et al., 1992; Haridy et al., $2000 ; 2006)$. It is well-known that the prevalence rates in

Corresponding Author: Khaled Sultan, Department of Parasitology, Faculty of Veterinary Medicine, Kafrelsheikh University, 33516 Kafr El-Sheikh, Egypt 
farm animals are in co-ordinance with the human rate of infection (FAO, 1982; Haridy et al., 2000). CE in farm animals causes considerable economic losses as well, due to the condemnation of the affected organs and the consequent reduction in productivity (Polydorou, 1981). Several surveys on the frequency of CE in farm animals were conducted in the Cairo and Delta regions of Egypt (Haridy et al., 1998; Rahman et al., 1992; Haridy et al., 2006; Sabri et al., 2005) with variable results of the prevalence rate of the disease. Little data exist for the disease's prevalence in ruminants in Upper Egypt. Consquently, this study was designed to determine the prevalence of $\mathrm{CE}$ in slaughtered ruminants of different kinds in some regions of Upper Egypt.

\section{MATERIALS AND METHODS}

During the period that elapsed between March, 2012 and February, 2013, a total of 4,498 animals (2,910 cattle; 398 buffalo; 820 sheep; 130 goats and 240 camels) were carefully inspected for the hydatid cyst during routine meat inspection in abattoirs at Hurghada, Qena, Sohag and Aswan, all located in Upper Egypt. These abattoirs were visited weekly throughout the study period. The macroscopically detectable cysts were individually collected in clean plastic bags, labeled and transferred to the laboratory for further examination. The fertility of the collected cyst was determined mainly by the presence or absence of protoscolices (Soulsby, 1982; Thompson, 1995). Data were computed and presented in tables.

\section{RESULTS}

Data on CE prevalence in the examined animals are shown in Table 1. The overall prevalence of CE in targeted localities revealed that out of 4,498 animals examined, $89(1.97 \%)$ had the hydatid cyst in their organs. As regards the variation among the animal species, CE infection was detected to be more prevalent in sheep $(14.1 \%)$ and goats $(13 \%)$ than in camels $(5 \%)$ and in cattle $(0.068 \%)$, while buffaloes were free from such infection (Table 1).

With respect to the infection rate in animal organs, our results are represented in Table 2. In general, livers examined harbored a higher percentage of cysts (39.3\%) than lungs $(32.5 \%)$ and other viscera $(2.2 \%)$. Infection in both liver and lungs was found to be $25.8 \%$. In sheep, hydatid cysts were more predominant in the liver $(39.6 \%)$ than in the lung $(24 \%)$. But hydatid cysts were found to occur preferentially in the lungs in camels $(50 \%)$ and in sheep (47\%), while camels had $33.3 \%$ cysts in the liver and in sheep $41 \%$ were found there. In cattle, cysts were found to infect the liver and lungs equally. In the current work and examination of the cysts (Table 2) indicated that $27.71 \%$ of the collected hydatid cysts were fertile. The cysts derived from camels were more fertile $(66.6 \%)$, than those from goats $(29.41 \%)$ and cysts in sheep were least fertile $(15.51 \%)$. All cysts obtained from cattle were sterile.

Table 1. Prevalence of cystic echinococcosis in different ruminant animals slaughtered in four abattoirs, Upper Egypt

\begin{tabular}{|c|c|c|c|c|c|c|c|c|c|c|c|c|c|c|c|}
\hline \multirow{2}{*}{$\begin{array}{l}\text { Animal } \\
\text { species/ } \\
\text { Abattoir }\end{array}$} & \multicolumn{3}{|l|}{ Cattle } & \multicolumn{3}{|l|}{ Buffaloes } & \multicolumn{3}{|l|}{ Sheep } & \multicolumn{3}{|l|}{ Goat } & \multicolumn{3}{|l|}{ Camel } \\
\hline & $\begin{array}{l}\text { Number } \\
\text { examined }\end{array}$ & $\begin{array}{l}\text { Positive } \\
\text { animals }\end{array}$ & $\%$ & $\begin{array}{l}\text { Number } \\
\text { examined }\end{array}$ & $\begin{array}{l}\text { Positive } \\
\text { animals }\end{array}$ & $\%$ & $\begin{array}{l}\text { Number } \\
\text { examined }\end{array}$ & $\begin{array}{l}\text { Positive } \\
\text { animals }\end{array}$ & $\%$ & $\begin{array}{l}\text { Number } \\
\text { examined }\end{array}$ & $\begin{array}{l}\text { Positive } \\
\text { animals }\end{array}$ & $\%$ & $\begin{array}{l}\text { Number } \\
\text { examined }\end{array}$ & $\begin{array}{l}\text { Positive } \\
\text { animals }\end{array}$ & $\%$ \\
\hline Hurghada & 900 & 0 & 0.000 & 120 & 0 & 0 & 820 & 58 & 7.07 & 104 & 13 & 12.50 & - & - & - \\
\hline Qena & 350 & 1 & 0.280 & 90 & 0 & 0 & - & - & - & 26 & 4 & 15.30 & - & - & - \\
\hline Sohag & 540 & 1 & 0.180 & 75 & 0 & 0 & - & - & - & - & - & - & - & - & - \\
\hline Aswan & 1120 & 0 & 0.000 & 113 & 0 & 0 & - & - & - & - & - & - & 240 & 5 & 4.8 \\
\hline Total & 2910 & 2 & 0.068 & 398 & 0 & 0 & 820 & 58 & 7.07 & 130 & 17 & 13.07 & 240 & 5 & 4.8 \\
\hline
\end{tabular}

Table 2. Predilection sites and fertility rates of hydatid cyst in different organs of ruminant animals inspected in the study

\begin{tabular}{|c|c|c|c|c|c|c|c|c|c|c|c|}
\hline \multirow[b]{3}{*}{$\begin{array}{l}\text { Animal } \\
\text { species }\end{array}$} & \multirow[b]{3}{*}{$\begin{array}{l}\text { Total number } \\
\text { of cyst }\end{array}$} & \multirow[b]{3}{*}{$\begin{array}{l}\text { Total number } \\
\text { of fertile cyst }\end{array}$} & \multirow[b]{3}{*}{$\begin{array}{l}\% \text { of } \\
\text { fertile cyst }\end{array}$} & \multicolumn{8}{|c|}{ Organs examined } \\
\hline & & & & \multicolumn{2}{|l|}{ Lungs } & \multicolumn{2}{|l|}{ Livers } & \multicolumn{2}{|c|}{ Lungs and livers } & \multicolumn{2}{|l|}{ Viscera } \\
\hline & & & & $\begin{array}{l}\text { No. of } \\
\text { cysts }\end{array}$ & $\%$ & $\begin{array}{l}\text { No. of } \\
\text { cysts }\end{array}$ & $\%$ & $\begin{array}{l}\text { No. of } \\
\text { cysts }\end{array}$ & $\%$ & $\begin{array}{l}\text { No. of } \\
\text { cysts }\end{array}$ & $\%$ \\
\hline Sheep & 58 & 9 & 15.51 & 14 & 24.0 & 23 & 39.6 & 19 & 32.0 & 2 & 3.4 \\
\hline Camels & 12 & 8 & 66.67 & 6 & 50.0 & 4 & 33.3 & 2 & & 0 & 0.0 \\
\hline Cattle & 2 & 0 & 0.00 & 1 & 50.0 & 1 & 50.0 & 0 & 0.0 & 0 & 0.0 \\
\hline Goat & 17 & 5 & 29.41 & 8 & 47.0 & 7 & 41.0 & 2 & 11.7 & 0 & 0.0 \\
\hline Total & 89 & 22 & 27.71 & 29 & 32.5 & 35 & 39.3 & 23 & 25.8 & 2 & 2.2 \\
\hline
\end{tabular}




\section{DISCUSION}

Generally speaking, the overall prevalence rate of $\mathrm{CE}$ found in our study is considered to be lower than that recorded in previous studies, both in Egypt and in other countries. For example, Rahman et al. (1992) reported CE percentages in camels, sheep, pigs, cows and buffaloes in Egypt as 31.0, 1.33, 4.62, 0.0 and $0.0 \%$ respectively. Moreover, (Haridy et al., 1998) also reported an increasing CE prevalence rate in Egyptian camels, from 5.5 to $8.2 \%$, between 1992-1995. Other countries also had a $\mathrm{CE}$ prevalence rate higher than our results showed: $17 \%$ recorded in Tunisia (Brahmi, 1973), $56.5 \%$ in Algeria (Euzeby, 1982), $80 \%$ in Morocco (Pandey et al., 1986), 53.7\% in Mauritania (Pangui and Ould, 1991) and 48\% in Libya (Ibrahem and Craig, 1998).

Other studies also reflect this variable rate of prevalence in the different animal species examined. For example, in Egypt, $0.33 \%$ of a total of 2,871,510 sheep slaughtered in the governmental abattoirs over five years (1995-1999) had hydatidosis (Haridy et al., 2006), while camels had an infection rate of $7.67 \%$ and cattle and buffaloes were clear of the infection altogether (Dyab et al., 2005). In the Delta region, the CE prevalence rate was $6.4 \%$ in sheep and $5.27 \%$ in goats (Sabri et al., 2005); in central Iraq the CE prevalence rate was $5.9 \%$ in sheep, $5.1 \%$ in goats, $4.9 \%$ in cattle and $20.4 \%$ in camels (Al-Abassy et al., 1980); in central Jordan the CE prevalence rate was $1.3 \%$ in sheep and $54 \%$ in goats (Dajani and Khalaf, 1981); and in. In northwestern Iran, the prevalence rate was $19.0 \%$ in sheep and 22\% in cattle (Nourian et al., 1997). In African countries, in north western Morocco the prevalence rate was $10.7,1.4$ and $80 \%$ in sheep, goats and camels respectively (Pandey et al., 1986); in Libya, the CE infection rate was reported to be $4.9 \%$ in sheep, $2.4 \%$ in goats, $2.7 \%$ in camels; and $15 \%$ in cattle (Kassem et al., 2013), while in Ethiopia, the prevalence rate was $35.15 \%$ in cattle, $11.78 \%$ in sheep, $4.9 \%$ in goats, $16.79 \%$ in camels, with pigs being free of the infection altogether (Fromsa and Jobre, 2011). In Egypt, the buffaloes in our study were likewise found to be free from any infection, which is in agreement with previous reports from Egypt (Rahman et al., 1992; Dyab et al., 2005), but in disagreement with reports from countries like Bangladesh, where $42.36 \%$ of the baffalo were found to be infected (Islam, 1982).

The variation in the prevalence rate of CE found in our results in Upper Egypt and those found in previous records in Egypt can be attributed to the demographical differences between Upper Egypt and the Cairo-Delta area. In Egypt, the main human population and livestock are concentrated in the Cairo-Delta area, where a moderate climate and the branching of the Nile River favor the existence and stabilization of the disease. Upper Egypt, on the other hand, has some unique characteristics, such as hot climate, long distances between cities and a lower population base, all of which aid in minimizing the opportunity for the $E$. granulosus life cycle to continue.

The variation in the CE prevalence rate found in the current study and that reported in other countries could be attributed to several factors, including applied control strategies, the farming system used and the state if a country's national development.

Results of infection rate in animal organs in the current study (Table 2) are in line with other the studies that report the liver, lungs, or both to be most often infected organs (Sabri et al., 2005). The organ involved may also depend upon the host species (Fromsa and Jobre, 2011) and on anatomical and physiological factors (Soulsby, 1982). In the current study, the cyst distribution found in the organs of afflicted animals is in agreement with previous studies (Rahman et al., 1992; Haridy et al., 2000; 2006; Fromsa and Jobre, 2011).

In general, livers examined harbored a higher percentage of cysts (39.3\%) than lungs $(32.5 \%)$ and other viscera $(2.2 \%)$. Infection in both liver and lungs was found to be $25.8 \%$. In sheep, hydatid cysts were more predominant in the liver (39.6\%) than in the lung (24\%). But hydatid cysts were found to occur preferentially in the lungs in camels $(50 \%)$ and in sheep (47\%), while camels had $33.3 \%$ cysts in the liver and in sheep $41 \%$ were found there. In cattle, cysts were found to infect the liver and lungs equally. The present data are in line with other authors (Ibrahem and Craig, 1998). Studies previously performed in Egypt reported that the hydatid cyst was localized in the liver (5.7\%) and in the lung (6.4\%) of sheep (Sabri et al., 2005).

The fertility rate of the hydatid cyst is an important factor in CE infection (Soulsby, 1982; Torgerson and Budke, 2003; Fromsa and Jobre, 2011). In the current work and examination of the cysts (Table 2) indicated that $27.71 \%$ of the collected hydatid cysts were fertile. The cysts derived from camels were more fertile (66.6\%), than those from goats $(29.41 \%)$ and cysts in sheep were least fertile $(15.51 \%)$. All cysts obtained from cattle were sterile. This fertility result is lower than previously reported in Egypt (49\%) Haridy et al. (1998) and in other countries such as Libya, where Ibrahem and Craig (1998) reported that $91.6 \%$ of examined cysts were fertile. 
The greater fertility rate of cysts from camel origin, followed by that in goats and sheep indicates the important role of camels and small ruminants in the transmission of animal and human CE in Egypt.

But a general conclusion can de drawn from our study, which shows that in Egypt, CE is more prevalent in small ruminants (i.e., sheep, goats) and in camels than it is in cattle. Buffaloes do not play any role in sustaining the CE infection. This is in line with previous studies in Egypt (Rahman et al., 1992; Haridy et al., 2000; Dyab et al., 2005) and also with studies done in neighboring countries (Ibrahem and Craig, 1998). This conclusion can be explained by the process of animal management of small ruminants, which favor $\mathrm{CE}$ infection: high interactions do occur between ovine and caprine herds and dogs and very frequently with camels.. But the rearing of cattle and buffaloes takes place largely indoors and that minimizes or prevents the interaction that can lead to contamination.

It is well known that the E. granulosus sheep strain (G1) is the predominating Echinococcus species involved in human $\mathrm{CE}$ and that there is also involvement of the camel strain (G6) that contributes to this problem (Torgerson and Budke, 2003; Magambo et al., 2006). Special programs for these animals should be employed to minimize the infection with E. granulosus.

The results represented here will help to provide more extensive and reliable information for further studies on hydatidosis, that can be used for planning and application of control measures for CE in human and animals.

\section{CONCLUSION}

So general note about CE in Egypt can be concluded that, $\mathrm{CE}$ is prevalent in sheep, goat and in camels than it is in cattle and buffaloes. Further studies on CE in animals are engorged.

\section{ACKNOWLEDGEMENT}

Researcher wish to express their thanks to the veterinarians in the abattoirs for their help throughout this study. Also, they are thankful to Dr. Akkie Bardoel for language revision of the manuscript.

\section{REFERENCES}

Al-Abassy, S.N., K.I. Altaif, A.K. Jawad and I.M. AlSaqur, 1980. The prevalence of hydatid cysts in slaughtered animals in Iraq. Ann. Trop. Med. Parasitol., 74: 185-186. PMID: 7436604
Brahmi, C., 1973. L'hydatidose Humaine et Animale en Tunisie. 1st Edn., Imprimerie de Trien, Lyon, pp: 104.

Dajani, Y.F. and F.H. Khalaf, 1981. Hydatidosis and Tenuicollosis in sheep and goats of Jordan: A comparative study. Ann. Trop. Med. Parasitol., 75: 175-179.

Dyab, K.A., R. Hassanein, A.A. Hussein, S.E. Metwally and H.M. Gaad, 2005. Hydatidosis among man and animals in assiut and aswan governorates. J. Egyptian Soc. Parasitol., 35: 157166. PMID: 15881003

Elshazly, A.M., M.S. Azab, S.N. ElBeshbishi and H.M. Elsheikha, 2009. Hepatic hydatid disease: Four case reports. Cases J., 2: 58-62. DOI: 10.1186/1757-1626-2-58

Euzeby, J., 1982. The biology of "tapewormsechinococci" The etiology and the epidemiolotgie of hydatid disease of man. Rev. Med. Vet., 133: 83-94.

FAO, 1982. Echinococcosis/hydatidosis: Surveillance, Prevention and Control: FAO/UNEP/WHO Guidelines. 1st Edn., FAO, Rome, pp: 147.

Fromsa, A. and Y. Jobre, 2011. Infection prevalence of hydatidosis (Echinococcus granulosus, Batsch, 1786) in domestic animals in Ethiopia: A synthesis report of previous surveys. Ethiopian Vet. J., 15: 11-33.

Haridy, F.M., B.B. Ibrahim and T.A. Morsy, 1998. Studies on hydatidosis in slaughtered camels in Egypt. J. Egyp. Soc. Parasitol., 28: 673-681. PMID: 9914691

Haridy, F.M., B.B. Ibrahim and T.A. Morsy, 2000. Sheep-dog-man. The risk zoonotic cycle in hydatidosis. J. Egyp. Soc. Parasitol., 30: 423-429. PMID: 10946504

Haridy, F.M., B.B. Ibrahim, A.M. Elshazly, S.E. Awad and D.M. Sultan et al., 2006. Hydatidosis granulosus in Egyptian slaughtered animals in the years 2000-2005. J. Egyp. Soc. Parasitol., 36: 1087-1100.

Ibrahem, M.M. and P.S. Craig, 1998. Prevalence of cystic echinococcosis in camels (Camelus dromedarius) in Libya. J. Helminthol., 72: 27-31. PMID: 9639897

Islam, S.A.W.M., 1982. Hydatidosis in buffaloes in Bangladesh. Rev. Sci. Technical Office Int. Epizoot., 1: 435-441. 
Kassem, H.H., A.M. Abdel-Kader and S.A. Nass, 2013. Prevalence of hydatid cysts in slaughtered animals in Sirte, Libya. J. Egyp. Soc. Parasitol., 43: 33-40. PMID: 23697014

Magambo, J., E. Nojorge and E. Zehyle, 2006. Epidemiology and control of echinococcosis in subSaharan Africa. Parasitol. Int., 55: 193-195. PMID: 16406684

Nourian, A.A., A. Ataeian and A. Hanilou, 1997. Hydatidosis/Echinococcosis in Zanjan Area, NorthWest of Iran. In: Who-OIE Manual on Echinococcosis in Humans and Animals: A Public Health Problem of Global Concern, Eckert, J., M.A. Gemmell, F.X. Meslin and Z.S. Paawlowski (Eds.), World Organisation for Animal Health, Paris, ISBN10: 929044522X, pp: 107-107.

Pandey, V.S., H. Ouhelli and M. Ouchton, 1986. Hydatidosis in sheep, goats and dromedaries in Morocco. Ann. Trop. Med. Parasitol., 80: 525-529. PMID: 3632099

Pangui, L.J. and A.E. Ould, 1991. Incidence of camel hydatidosis in Mauritania. Bull. Anim. Health Product. Afr., 39: 25-26.
Polydorou, K., 1981. Animal health and economics. Case-study: Echinococcosis with a reference to Cyprus. Bull. Int. Dis. Epizoot., 93: 981-992.

Rahman, M.S., S.M. Sokar and S. Dahab, 1992. Comparative studies on hydatidosis in farm animals in Egypt. Dtsch Tierarztl Wochenschr, 99: 438-440. PMID: 1459031

Sabri, J.H., M.A. Hassan, M.Y. Ramadan and N.O. Khalifa, 2005. Hydatidosis in sheep, goat and human contacts. Benha Vet. Med. J., 16: 2-2.

Soulsby, E.J.L., 1982. Helminths, Arthropods and Protozoa of Domesticated Animals. 7th Edn., Philadelphia Lea and Febiger, ISBN-10: 0812107802, pp: 809.

Thompson, R.C.A., 1995. Biology and Systematics of Echinococcus. In: Echinococcus and Hydatid Disease, Thompson, R.C.A. and A.J. Lymbery, (Eds.), CABI, Wallingford, ISBN-10: 0851989217, pp: 496-496.

Torgerson, P.R. and C.M. Budke, 2003. Echinococcosis-an international public health challenge. Res. Vet. Sci., 74: 191-192. PMID: 12726737 